\title{
印尼建国大学市场营销专业汉语教育问题与对策 THE PROBLEMS OF AND SOLUTIONS TO CHINESE EDUCATION FOR MARKETING COMMUNICATION AT BINUS UNIVERSITY
}

\author{
Theresia \\ Chinese Department, Faculty of Humanities, BINUS University \\ Jln. Kemanggisan Ilir III No. 45, Kemanggisan-Palmerah, Jakarta Barat 11480 \\ antonia_theresia@yahoo.com
}

\begin{abstract}
Nowadays in Indonesia, more people realize the importance of using Chinese language. Therefore, at Binus University, Mandarin is taught not only in Chinese Literature Department, but also in non-Chinese Literature Department. Because the curriculum is still relatively new, students who have never studied Chinese language find some difficulties. The author through observations in the classroom found some problems that arise during the teaching and learning session. Through this paper, the author hopes to help to solve existing problems, to increase the level of Chinese language knowledge, and help to increase students' interest in Chinese language.
\end{abstract}

Keywords: BINUS University, marketing communication, Chinese education, problems, solution

\section{摘要}

现在在印尼, 汉语的地位越来越重要, 越来越多的人都开始想要学习汉语。因此, 在印尼建国大学 不仅开设了汉语专业, 而且最近在非汉语专业, 如本文提到的市场营销专业也开设了汉语课。因为市场 营销专业汉语课的开设时间还不是很长, 所以大部分没接触过汉语的学生开始学习汉语的时候感觉还是 很困难和吃力。笔者希望用课堂观察的方法发现这个专业学生学习汉语过程中出现的具体问题, 并通过 本论文能够对解决学生们学习汉语的问题提供一些帮助, 同时, 能提高学生的汉语水平, 使学生对汉语 能够更感兴趣。

关键词：印尼建国大学；市场营销专业；汉语教育；问题；对策 


\section{引言}

在当前全球化的时代背景下，有很多种语言都进入了印度尼西亚，比如：法语、德语、英 语、日语、汉语等等, 其中发展最快的语言就是英语和汉语。现在, 这两种语言在国际上的地 位都很重要, 尤其是汉语, 在印尼成为除了英语之外最重要的第二外语, 人们也对汉语越来越 感兴趣。在印尼, 学习汉语有很重要的作用, 汉语的学习能够培养更多优秀的学生, 使他们拥 有更好的交际交往能力来面对全球化时代的到来。

近年来, 随着印尼政府对华政策的调整, 学习汉语的人越来越多: 现在从幼儿园到大学都 有汉语课, 汉语的补习班也越来越受到大家欢迎。此外, 中印两国之间的贸易文化交流也在不 断地迅速发展, 汉语教育在印尼面临着一个新的发展时期。因此, 汉语在印尼越来越受到重 视。在建国大学, 不仅在中文系有汉语课, 在非汉语专业, 尤其是市场营销专业, 也开设了汉 语课程。2011 年，笔者有机会在建国大学实习并且给市场营销专业的学生讲授汉语课。

在实习期间, 笔者认为市场营销专业的学生汉语水平还停留在初级阶段, 他们在听、说、 读、写等方面还存在很大的问题。老师们希望学生能对汉语课更感兴趣, 同时也希望能找到更 好的教学方法来提高学生的汉语水平。因此, 笔者将要研究教师对市场营销专业学生的教学问 题以及探讨解决问题的方法。

本论文主要是要研究市场营销专业学生学习汉语遇到的问题与教学对策。笔者希望通过本 研究所提出来的问题与对策不仅能够帮助印尼汉语教师提高教学质量, 也能够帮助学生提高他 们的听、说、读、写能力。对学生来说, 有了适合他们的教学方法才能对汉语产生浓厚的兴 趣; 对教师来说, 有了适合的教学对策才能很好地解决学生学习中的问题。所以笔者写了关于 市场营销专业学生学习汉语的教学问题与对策。

\section{研究方法}

笔者主要采取定量与定性两种方法。定量方法: 采取问卷调查的方式, 调查学生的汉语水平与 影响学生的汉语水平的原因。定性方法: 通过观察学生在课堂上的学习态度与学习情况, 了解和掌 握学生的汉语水平与影响学生的汉语水平的原因, 并且找出教师在教学中所存在的一些问题。此 外，笔者也搜集并且研读了相关的汉语教学法书籍、论文，以及一些教材。

\section{内容}

\section{印尼建国大学市场营销专业学生学习汉语的情况}

在建国大学，市场营销专业成立于 2007 年，第一年该专业有学生 350 名，在 2010 年已增 加到 1140 名学生, 现在大约有两千多名学生。

这个专业是新的专业, 也是建国大学第一个开设汉语课程的非汉语专业。这门汉语课的开 设不仅是为了能够使学习过汉语的学生进一步提高他们的汉语水平, 也是为了使那些从未接触 过汉语的学生, 能够增加一门新的外语技能, 从而, 在未来能有更好的发展。 
因此, 印尼建国大学开设了这门汉语课。汉语课是这个专业的必修课, 分别开设在第三学期和 第五学期, 每个学期有 4 学分, 总共有 8 学分。平时上课要求教师每课必须要在一个课时内（100 分钟）完成, 一周两课时。如果学生在考试中得到了“D”, 他们就需要重修这门课。

市场营销专业的汉语课分别叫做汉语 (一) 和汉语 (二)。老师和学生用的教材是《汉语会话 301 句 (上，下)》。市场营销专业的学生很多，一个班大概 40-50个人。

汉语（一）和汉语（二）主要教的是口语。可是由于在市场营销专业的考试有两部分，笔试与 口试:

汉语 (一): 其中考试与期末考试有拼音

汉语（二)：其中考试有拼音，期末考试没有拼音。

所以, 老师不但要给学生讲授口语, 而且也要教他们一些语法知识和汉字知识。

\section{印尼建国大学市场营销专业汉语课存在的问题}

在实习期间，笔者发现在市场营销专业的汉语课问题有很多，不仅是在学生方面，而且在 教师教学方面也有问题。因为, 市场营销专业是非汉语专业, 学生对汉语都是刚刚有所接触也 不太了解, 所以对汉语的学习热情不是很高。通过课堂教学与观察, 笔者发现以下的一些问 题:

\section{学校教学管理方面}

1. ) 课堂设置。以前汉语课在第四学期和第五学期, 但当笔者在印尼建国大学实习时, 汉 语课已经改在第三学期和第五学期。所以, 笔者认为, 这样的课程安排, 会影响学生学习的连 续性过程, 中断一个学期的教学, 会使学生遗忘之前学习的内容, 从而阻碍了下一阶段的学 习。2.）教师配备。由于学生的汉语水平有限所以市场营销专业的汉语课必须全部由印尼老师 老师来授课，不能由中国老师来授课。这样多少会对提高学生汉语水平有一定的影响。3.）教 材配备难易程度。很多汉语教师反映学生用的教材有点儿难, 不太适宜他们现在的水平, 课程 也太多。一个学期要学一本书, 这样, 就加重了老师和学生的负担。4. ) 班级设置。每个班的 学生人数过多, 导致了教师控制整个课堂有一定的难度。而且也不能保证每个学生都有足够的 练习机会。5.) 课时安排。每周教学时间比较紧张, 一般学校会要求教师一个课时 (100 分 钟）必须讲完一课内容, 学生练习时间显然不够。

\section{教学过程中存在的问题}

\section{教师方面}

1. 老师自身管理课堂能力还不够

因为市场营销专业学生的汉语课每班都有 40-50 人, 比中文系的人数要多很多, 因此一位 老师在课堂上往往控制不了那么多的学生, 加上学生普遍都觉得汉语课比较难, 所以一旦 他们听不懂, 注意力就不能集中, 开始做别的事情, 老师就控制不住他们了。

2. 老师对学生要求不够严格

对老师来说, 大学生的性格和人格都已经发展的比较成熟, 所以老师对待学生像朋友 一样, 而不是像对待中小学的学生一样, 结果一部分学生就觉得老师不够严厉, 不尊重老 师给他们的自由, 上课比较散漫, 不听老师的话。 
3. 老师的汉语水平

到目前为止, 印尼老师的汉语水平还比不了真正的中国老师。印尼汉语老师有缺点, 比如印尼 老师在教学的过程中会用到很多母语来给学生解释, 这样就使得学生对母语形成一定的依赖,

不会想用汉语来回答问题, 或是进行思考。

4. 老师的教学方法

目前在汉语课上, 老师的教学法都比较单一, 对于大学生来说比较枯燥, 不容易引起他们的兴 趣, 由于每班学生人数比较多, 所以老师应该要想办法组织设计一些比较活泼而又适合学生人 数的活动, 而不应该因为人多不好组织就不做课堂活动。

\section{学生方面}

学生有普遍的迟到问题。比如, 9:20 点上课, 学生 10:00 点才来。这样会影响到学生的学习 进度和教师本身的教学进度。

学习注意力不够集中的问题。老师读完一个生词, 让学生重复读一遍, 但是大部分学生都不能 专心地跟读, 学习的态度不是很认真。老师讲课的时候, 学生的注意力通常也不能集中在课堂上。

学习热情不够高的问题。学生认为汉语是很难学的语言, 而且对他们来说也不是一个非常必要 的语言技能。所以, 大多数学生都不重视汉语课的学习。

\section{针对印尼建国大学市场营销专业汉语课的教学对策}

通过考察以上的这些问题, 笔者也想要研究如何解决那些问题。对老师来说面对这样专业的学 生，就要更加耐心、慢慢地给学生讲课才有效。

英国教育理论家赫斯特通过课堂研究认为, 有效教学最基本的条件有三种: 一是学生不仅学到 了教师传授的大部分学科知识, 而且学到了许多其他知识; 二是课堂教学活动结束以后, 学生还在 继续研究和探讨上课内容; 三是不能强迫学生学习, 而是让学生渴望学习。

老师也不希望强迫学生来学习他们不喜欢的课, 但这门课又是一门必修课, 所以, 即使课程内 容有一定的难度, 老师还是希望学生通过一段时间的学习, 在不断调整教学方法的前提下, 学生在 汉语学习中能够有所收获。所以, 笔者就研究了以下几种解决方法。

\section{学校管理方面的对策}

1. 1. 课程设置。笔者认为市场营销专业的汉语课应该两个学期连在一起上课, 这样, 学生会有一个 连贯性的学习过程, 有助于学生提高汉语水平。

2. 教师配备。让不懂印尼语的中国教师授课, 目前还不太可能, 所以应该要求印尼老师在课堂上 要减少用母语来讲课, 尽量多使用汉语, 让学生更熟悉汉语的语言环境。

3. 教材难易程度。学生目前用的教材比较合适, 但是由于学生基础比较不好, 所以笔者认为还应 该选用一些更加简单易懂的教材。

4. 班级设置。之前每个班的学生人数太多, 每班有 40 多人, 所以汉语课可以减少为每个班 20 人, 进行小班式教学, 使老师能够很好的控制课堂节奏, 学生也能更加集中精神学习。

5. 课时安排。笔者认为, 如果一课内容分成两个课时来讲, 学生对知识的掌握会更加牢固, 练习 时间也会很充分。 


\section{教学过程存在问题的对策}

\section{教师方面}

1、老师对学生要严格要求, 制定相应的奖惩措施, 约束学生在课堂上的表现, 这样学生也会 加强对汉语课的重视。

2、老师要提高自身管理和控制课堂的能力, 调动学生的学习兴趣, 有效地进行教学。

3、学校应该注意两方面的问题: 一是招聘教师的时候应该对教师的汉语水平有更高的要求; 二是增加在职教师汉语培训的机会。

\section{学生方面}

笔者认为在课堂上需要多些活动, 比如: 游戏、小组讨论、会话表演等, 来提高学生对汉 语的学习兴趣, 活跃课堂氛围、提高学生的学习效率。活动理论可以在每个教学部分中体现出 来, 所以下面要介绍一下有关活动理论的内容。

活动理论由维果茨基创立, 他的继承者 Leontiev 和 Engestrom 发展了该理论。社会理论中 的 “活动” 包括活动的主体 ( subject)、活动的目标和动机 (object)、达到目标的行动 (actions) 以及行动的操作手段 (operation) 四个要素, 活动会因为以上要素的不同而不同。 在四个要素中, 目标和动机尤为关键, 因为活动之间的区别主要在于目标和动机。

社会文化理论进一步区分了活动与任务。任务是计划, 比如, 教师在课前安排好本课要达 到目标, 具有稳定性; 活动是个体完成任务时的实际表现, 比如学生为了完成任务是如何学习 的，因为每个个体的动机不同，活动也不同，所以活动具有动态性。1

笔者在实际的教学中发现, 课堂上多做一些目的性强的活动能够让学生对学习产生更浓厚 的兴趣, 即使遇到困难, 学生也愿意努力的去克服。于是, 笔者认为以下几种典型的活动形式 可以分别应用在不同的方面的汉语教学中, 以提高课堂的教学效率: 问答题教学法、话剧和角 色扮演教学法、讨论式教学法、小组情景会话等。

\section{结论}

本文以印尼建国大学市场营销专业汉语教学为对象, 主要研究了该专业的学生在汉语学习 中存在的问题, 并提出了相应的解决方法和对策。

笔者通过课堂调查, 调查了印尼建国大学市场营销专业的学生学习汉语的问题主要体现在 教师和学生两个方面: 教师方面, 老师自身管理课堂能力不够、对学生要求不够严格、自身汉 语水平、教学方法; 学生方面, 迟到问题、学习态度问题、汉语水平问题等。

笔者针对以上问题提出了一些解决方法, 并且认为现在教师所用的教学方法需要更全面, 更具有灵活性, 课堂环节除了传统的教学方法, 还可以创造更多的机会让学生参与到教学中, 多让他们开口练习, 多一些活动增加他们的学习兴趣。 
笔者以上提出的这些解决方法和对策, 并不能涵盖学生汉语学习中出现的所有问题, 并且 还有很多疏漏和不足, 希望日后争取通过进一步的努力学习和在老师的帮助指导下, 对该专业 学生汉语学习的问题, 能够找到更多有帮助的、有利于提高学生汉语水平的方法和对策。

\section{参考文献}

黄伯荣、廖序东．现代汉语上册 [M] . 北京：高等教育出版社， 2007

叶蜚声、徐通铭. 语言学纲要. 北京. 北京大学出版社, 1997

刘广徽、金晓达. 汉语普通话语音图解课本 [M]. 北京: 北京语言大学出版社, 2007

姜丽萍. 对外汉语教学论 [M]. 北京: 北京语言大学出版社, 2008

王建勤．第二语言习得 $[\mathrm{M}]$ ．北京：商务印书馆，2010

周健．汉语课堂教学技巧 325 例 [M] . 北京：商务印书馆，2009

赵金銘．汉语可以这样教 [M]．北京：商务印书馆，2010

张和生. 对外汉语课堂教学技巧研究 [M]. 北京: 商务印书馆, 2006

李晓琪. 对汉语汉语口语教学研究 [M]. 北京: 商务印书馆, 2006 